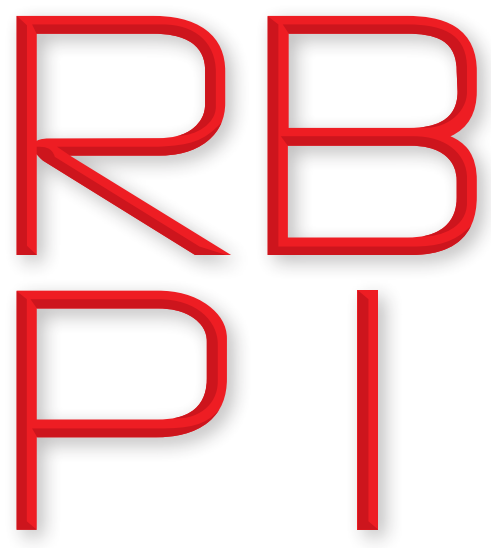

Revista Brasileira de Política Internacional ISSN 1983-3121

http://www.rbpi.info

\section{Tony Tai-Ting Liu}

National Chung Hsing University, Graduate Institute of International Politics, Taichung, Taiwan (stanggoftibia1984@yahoo.com.tw)

iD ORCID ID:

orcid.org/0000-0002-3328-3903

\section{Copyright:}

- This is an open-access article distributed under the terms of a Creative Commons Attribution License, which permits unrestricted use, distribution, and reproduction in any medium, provided that the original author and source are credited.

- Este é um artigo publicado em acesso aberto e distribuído sob os termos da Licença de Atribuição Creative Commons, que permite uso irrestrito, distribuição e reprodução em qualquer meio, desde que o autor e a fonte originais sejam creditados.

\title{
Teaching IR to the Global South: Some Reflections and Insights
}

DOI: http://dx.doi.org/10.1590/0034-7329201600204

Rev. Bras. Polít. Int., 59(2): e004, 2016

\section{Abstract}

The complexities of global politics in the new century have rendered traditional approaches of IR obsolete in many ways. This article attempts to point out the inadequacies of Western/US centric perspective of IR in interpreting current developments. This article argues that the teaching of IR in the globalized age should take into account different contexts and encompass more alternative concepts.

Keywords: Teaching of International Relations; Global South; Taiwan.

\section{Acknowledgements}

Funding information: Ministry of Science and Technology, Taiwan (105-2917-I-005-001).

Received: September 29, 2015

Accepted: June 13, 2016

\section{Introduction}

$I^{t}$ $t$ is no exaggeration that International Relations (IR) is a discipline that emerged from the ashes of war. Although interstate wars have stretched far back into history than the First Great War of the past century, it was not until the suffering and deaths of millions before the study of interstate relations was introduced. Institutionally speaking, the study of IR was born in 1919 when David Davies, British philanthropist and Liberal MP in Wales, endowed a Chair as a memorial to the students of the University College of Wales, Aberystwyth, who had fought and died in the conflict (Booth 2014, 11). Students of this new subject were challenged, as they still are, to have a remarkable and cross-disciplinary knowledge about how human society works globally (Booth 2014, 11). While the world in 2016 is vastly different from the world in 1919, the expectation for students to develop critical thinking and problem solving skills remains largely unmoved. 
Recognizing the complexities of international relations and global affairs in the new century, this article attempts to point out the inadequacies of mainstream Western/US centric perspective of IR in interpreting current developments. Specifically, with the classroom become more internationalized following globalization, teaching IR today thus demands a higher level of cultural awareness that acknowledges student diversity and state context. This author argues that the IR classroom today should emphasize the importance of context and encompass more alternative concepts in order to reflect diversities in the real world.

The ensuing discussion is organized as follows. Part 1 briefly describes how globalization has transformed classrooms in Asia. Part 2 notes critical thinking as a main goal of teaching IR and elaborations on history and geography, non-tradtional issues and various theoretical concepts as beneficial towards the goal. Part 3 draws on the themes noted in the preceding section and use the case of Taiwan to demonstrate the importance of context and the danger of a monolithic theoretical discourse. This article concludes with suggestions on improving critical thinking among students and maintaining an open space for discussions in the IR classroom.

\section{Globalization, Internationalization and the Changing Classroom in Asia}

Despite the cliché that advancements in technology and telecommunication have greatly shortened the distance between peoples and facilitated transnational exchange and communication, the phenomenon known as "globalization" has also made its imprints on education. In contrast with just two decades ago, the instructor today has more tools at his or her disposal to fulfill the task of teaching. For example, through the personal computer (PC) and the internet, the instructor could more easily communicate with the student, whether through correspondences through electronic mails (emails) or social networking interfaces such as personal blogs, Facebook or Twitter, while online media channels such as Youtube provide the instructor with an abundance of footages to serve as visual aids in the classroom. In addition, the internet not only makes possible the interconnection of classrooms through software such as Skype, ${ }^{1}$ but also makes long distance learning and open/online classrooms a common reality today. Virtual initiatives such as the MIT Open Courseware and Open Yale Courses that provide, among other fields, open access to courses on International Relations spanning IR theory, US foreign policy and human rights studies, which would not have been possible without the internet and related advancements. $^{2}$

\footnotetext{
1 For example, in the fall of 2014, this author participated in a class on "China and the Korean Peninsula" hosted jointly by the Graduate Institute of International Politics at National Chung Hsing University in Taiwan and the Graduate School of International Studies at Yonsei University in South Korea via video conferencing. The experience demonstrates how technology is transforming the classroom experience.

2 See MIT Courseware for an example of how IR is taught through the internet today. MIT Courseware, <http://ocw.mit.edu/courses/ find-by-topic/\#cat=socialscienceひsubcat=politicalscienceひspec=internationalrelations $>$.
} 
On the other hand, similar to the instructor, the student has more learning tools at hand than before. The prevalence of electronic books and subscriptions are slowly changing the reading habit of students while electronic databases provide access to multiple sources through a one stop interface. Besides serving as portable PCs that could be used to access the internet, the tablet or pad also prompted the development of functions such as Podcast, RSS and App that greatly expand the possibilities for learning and communication. In a sense, learning is no longer restricted to the traditional classroom or lecture hall with all eyes focused on the instructor; learning is no longer limited to space and time.

Technological advancements aside, perhaps even more significant is the physical change in classrooms in terms of student makeup, or in macro terms, the internationalization of higher education. In the new century, the leveling of state borders has led to a general increase in the number of students pursuing higher education abroad. For example, the number of international students studying in the US increased by approximately three hundred thousand compared to almost a decade ago, leaping from 564,766 persons for the school year 2005/06 to 886,052 persons in 2013/14. ${ }^{3}$ According to Project Atlas (2015), a US based agency established in 2001 to track the number of students traveling to another country in pursuit of higher education, the number of so called "migrant students" has increased from 2.1 million students in 2000 to 4.5 million students globally in 2014. In the report Vision 2020: Forecasting International Student Mobility, the British Council (2004) projected the number of global migrant students to reach approximately 5.1 million by 2020 .

Asia is no exception to the global trend as countries such as Taiwan, Japan and South Korea have all witnessed an increase in international students in recent years. In 2014, in terms of the number of international students, Taiwan hosted 43,957 persons; Japan hosted 184,155 persons; and Korea hosted 84,891 persons (ROC Ministry of Education 2013, 56; JASSO 2015; Jung 2015). Noting the growing number of migrant students, and perhaps also taking into account demographic change generated by delayed marriage and low fertility rate, the aforementioned countries have all established grand schemes and ambitious goals to attract more foreign students and internationalize higher education.

In Taiwan, while the government pledged to attract twenty thousand students to come to the country every year, it has also introduced the Plan to Develop First-class Universities and Top-level Research Centers, or so called “five year fifty billion NTD” plan (approximately 1.67 billion USD), to support internationalizing efforts. ${ }^{4}$ In Japan, Tokyo introduced the Global 30 Project in 2008, a 15 billion yen (1.25 billion USD) initiative that seeks to upgrade 30 higher education institutions in Japan into "internationalized centers" that would promote two way exchange with the world through the recruitment of foreign students — targeted at thirty

3 "International Students in the United States," <http://www.iie.org/Services/Project-Atlas/United-States/International-Students-In-US>.

4 "Ma Pledges to Push 'Soft Power Diplomacy'," <http://www.chinapost.com.tw/print/227875.htm>. 
thousand students - and the encouragement of domestic students to study abroad. ${ }^{5}$ In Korea, Seoul established the Study Korea Project in 2004 and aimed to attract one hundred thousand foreign students by $2012 .^{6}$

\section{Teaching International Relations in a Changing World}

For the instructor, the globalization of higher education brings about both benefits and challenges. While the biggest advantage of the "opening up" of classrooms is perhaps the cultural diversity and perspectives brought along by foreign students, paradoxically, the toughest challenge is also how to respond to the rapid transformations in the student body. Such problem stands out particularly in countries such as Taiwan, Japan and Korea, where cultural homogeneity is one of the chief characteristics of society. The diversity introduced by internationalization of the classroom means that certain assumptions are no longer as true today as in the past. Regarding the teaching of a culturally sensitive subject such as International Relations, a diverse student body poses questions against fundamental assumptions on the world today and the key issues that should be addressed in class.

While the instructor may choose not to respond to the changing classroom and follow "the traditional way of doing things" - whatever that may be - out of convenience, such a choice risks the potential failure to equip students with the ability to understand and cope with an ever evolving world while curtailing the possibility for discussions on various issues pertaining to political, economic, historical, cultural, ethnic and gender sensitivities. Many studies have argued that the ability to address issues critically or "critical thinking," lies at the center of a liberal education and remains a particularly valued asset in a complex environment (Dam and Volman, 2004; Frueh et al., 2008). As Shakirova $(2007,42)$ points out, "critical thinking skills are important because they enable students to deal effectively with social, scientific and practical problems." In other words, students who are able to think critically are able to solve problems effectively (Snyder and Snyder, 2008, 90). On the other hand, as Deardorff (2013, 368) observes, whenever the [instructor] represents a different socioeconomic segment of society, political perspective, cultural or racial group, or other relevant characteristic than the majority of students in the class, there is the clear possibility that learning will be compromised.

Hence, in order to avoid the dangers of intellectual intransigence to the detriment of student development, it is important for the instructor to acknowledge differences in a multicultural

5 For more details about the Global 30 Project and Japan's internationalization efforts, see: Chris Burgess, Ian Gibson, Jay Klaphake and Mark Selzer, "The 'Global 30' Project and Japanese Higher Education Reform: An Example of a "Closing In" or an "Opening Up”?" Globalization, Societies and Education 8, no.4 (2010): 461-75.

6 National Institution for International Education (Korea), "Study in Korea," <http://www.studyinkorea.go.kr/en/sub/overseas_info/korea_edul edu_student.do>. 
setting and design the course accordingly. In terms of IR, such an endeavor may entail the search for a delicate balance in content between history and current affairs, traditional and non-traditional security issues, and Western and non-Western theories. While the task may not be easy and indeed, a complicated one to accomplish, the difficulty of balancing among the issues speaks directly to the complex nature of international or global politics in the new century. Noting the wide range of issues thus presented for consideration, this author seeks to emphasize that regardless of the final content, the topics addressed should expose students to both old and new challenges that link the past, present and future of international relations while giving students the opportunity to recognize culturally or historically specific contexts that may be at variance with their personal experiences.

\section{Connecting the Past and the Present: History, Geography and Current Affairs}

Setting out with the premise of enhancing the student's critical thinking ability, the connection between history and geography with current affairs should serve as the mainstay of a class on International Relations. In other words, among other considerations, history and geography should serve as the basic starting points for discussions on international affairs (Blaney, 2002, 271; Acharya, 2011; Tickner, 2011; Leira, 2015; Behera, 2016, 2). Without recognizing the differences in how and where peoples came about, all too often the dominant or "mainstream" historical narrative with built-in assumptions becomes uncontested and accepted as such. On the other hand, in terms of geography, discussions on globalization and the collapsing of borders have often rendered concerns for geographic location obsolete, at a time when where one is positioned on the map remains crucially relevant in international relations. In a sense, critical thinking only begins when one can start to take into account different conditions that do not conform nicely to textbook descriptions or common knowledge.

In contrast with the global north or so called "developed world" where International Relations grew as a discipline, the global south - South and Southeast Asia, South and Latin America, Africa and the Middle East - seems to be a vast region detached and irrelevant to the discipline. Notwithstanding now problematic conceptions such as "yellow peril" and the "white man's burden," historically, the general tendency to conceive the South in large swaths such as Asia, Africa and the Middle East, or under sweeping titles such as the Third World or the developing world, fails to recognize the different cultures and histories among nations contained within the regions (Smith, 2009, 270). In this regard, Samuel Huntington's Clash of Civilizations thesis $(1993,2011)$, which describes the world as consisting of nine major civilizations that may potentially clash, is a particularly contentious example. It is against such 
broad, overarching claims that the instructor should invite students to challenge, based on different historical experiences and cultural makeup.

Meanwhile, histories are often shaped by geography or where one is located in the world. Yet despite such claim, globalization and its flattening effect on international relations - a phenomenon perhaps best expounded by American news columnist Thomas Friedman (2007) - has effectively weakened the strength of state borders to demarcate sovereignty and independence. While the state remains a useful analytical concept in international relations in relation with other states and non-state actors, the geographical relationship between different states remain under emphasized. Although the discipline of geopolitics continues to stress the connection between geography and political interests, ${ }^{7}$ it is less clear whether economic, social and cultural implications are explored as well. As in the case of history, depending on where one is situated, the outlook on the world is greatly varied. For example, following China's economic rise, while many countries welcome the strengthening of economic relations with the rising power, one should not presume the perception and strategy undertaken towards China is necessarily similar across the world. Even within the global south, Southeast Asia, Latin America and Africa's response and reaction towards China may be vastly dissimilar due to geographical distance.

\section{Interpreting Realities and Alternative Readings: Western and Non-western Traditions}

Beyond the past, present and future, an important feature of International Relations is the multiple lenses offered to one to interpret or read into empirical events. Since the introduction of theories into IR, much academic debate has centered on the ontology, epistemology and methodology of the discipline. While the great debates are useful in understanding how IR takes its form today, cultural assumptions built into the theories are often under emphasized (or not emphasized) and taken for granted in classrooms (Kayaoglu, 2010, 195; Chen, 2012, 465-66). Although the origins of IR should suggest the fact that most theories in the discipline are the product of developments in the United States or the United Kingdom, the situation may not be clear for new learners of the discipline, especially abided by the fact that knowledge disseminated through the internet in the age of globalization may not have a discernable origin in the first place. Hence to a large extent, the instructor is left with the responsibility of uncovering cultural biases and other nuances in class.

While mainstream theories such as realism, liberalism and constructivism remain useful analytical tools in examining empirical events, the conclusions that are drawn may sometimes develop into misleading generalizations that consult new learners. For example, a realist interpretation of international relations characterized by anarchy will easily reach the conclusion

7 See: Robert D. Kaplan, The Revenge of Geography: What the Map Tells Us About Coming Conflicts and the Battle Against Fate (New York: Random House, 2012). 
that (military) power is the best guarantor of state survival and interests (Morgenthau, 2005; Waltz, 2010; Mearsheimer, 2014a). Yet such deduction overlooks the fact that power takes many forms and the military is merely a particular form of power (Nye, 2005, 2011; Naim, 2014). At the same time, states have different capabilities and confront different challenges; prioritizing military buildups and advancements is merely one of many options in the post-Cold War period that may not have equal weight among large and small states. A liberalist interpretation of international relations on the other hand, paints a picture of the world as a free order governed by norms and institutions (Keohane, Nye and Hoffman, 1993; Keohane, 2005; Keohane and Nye, 2011). Yet little disillusions should be given to the fact that Woodrow Wilson and the Bretton Woods system provide important inspirations for liberal theorists. The ideals and values advocated by Wilson and harbored at Bretton Woods are not necessarily shared by all non-Western states.

In short, the point is not to demonstrate the fallibility or infallibility of specific theories, but to encourage critical thinking among students - noting the unique condition of each state - when applying analytical tools to a given event. Critical perspectives that deconstruct realities enable students to begin questioning and challenging general wisdom that often becomes sacred knowledge over time. While critical lenses may not necessarily bring about answers, as L.H.M. Ling retorts, however, "theory does not necessarily need to correspond with realities...... thinking and debating about theories may be purely in the interest of knowledge creation." ${ }^{8}$ In such case, Ling $(2000 ; 2014 a)$ has argued that IR theory has been a realm largely dominated by "hyper-masculine, Eurocentric, whiteness" (or HEW for short). From a feminist perspective, to a disproportional extent, IR theory tends to emphasize masculine traits such as military and political power to the neglect of emphasis on notions such as emotions (Ling, 2014b). Lene Hansen (2000), among others, has also made similar claims. Feminist theory is but one of many lenses that provide a different reading on reality. While theory in itself may not necessarily lead to solutions, challenges raised by alternative interpretations of realities may stimulate further thoughts and debates with policy implications (Puchala, 1997).

\section{Contextualizing Taiwan and International Relations}

Noting the points outlined in the previous section, this author examines the case of Taiwan, an island nation off the coast of Mainland China. In terms of territorial size - a traditional indicator of power - at 36,193 square $\mathrm{km}$, the country is only bigger than Singapore and Brunei in Southeast Asia, microstates in Oceania (such as Fiji and Papua New Guinea) and a handful of small states scattered across Africa and Central America (such as Gambia and Belize). In comparison with Mainland China, Taiwan is militarily weak and does not possess

8 Ling made the comment at the International Workshop on Theorising China's Rise and Beyond International Relations in 2016, which this author had the opportunity to preside. 
nuclear weapons. Challenged by the so called "One China" principle, Taiwan, also known as the Republic of China (ROC), is not a member of the United Nations and receives official diplomatic recognition from only 22 states. ${ }^{9}$ However, Taiwan is a thriving democracy. According to IMF (2015) statistics, the Taiwanese economy is also the twentieth largest in the world, giving the island nation the status of a middle power in the global economy.

Considering the situation of Taiwan, teaching IR on the island demands the instructor to take into account the island nation's unique status in the world and the implications such status entails. Since 1949, Taiwan has played a critical role in the fluctuating relationship between China and the US while occupying a strategic position off the shore of Mainland China geographically. As a "state" that lacks widespread diplomatic recognition, Taiwan is the problematic exception that does not fit nicely with the principle of sovereignty that upholds international order. Interestingly, the island nation's constricted diplomatic situation has brought many students from the global south to study in its classrooms, with a significant portion of students coming from states that have diplomatic relations with Taiwan. ${ }^{10}$ In 2008 , following the reconciliation of relations between China and Taiwan, Taipei began to accept Mainland Chinese students in its classrooms, a move that further increased the global southern makeup of the island's student body.

Given the conditions that govern Taiwan, the local IR instructor finds himself in a unique position in class, confronting a large number of students with experiences that are vastly different from the island's developed situation while getting to play with the fact that concepts such as "state" and "sovereignty" may not necessarily hold true for Taiwan without qualifications. In a sense, the case of Taiwan provides the instructor with an opportunity to rethink the goals of teaching IR and emphasize critical thinking - looking into the historical, cultural and geographical conditions and how the conditions shape interactions with the world - as the starting point for considering the international relations of any state.

The following section seeks to briefly trace the development of Taiwan's international relations in history in order to demonstrate that critical thinking skills can only be developed through a more rounded understanding of a subject. On the other hand, the discussion also describes how mainstream theories often monopolize topic discussions and drive out the potential for alternative readings on the island. While other views may not necessarily generate better explanations to a topic, this author argues that widening and preserving a space for discussions is important for the advancement of critical thinking ability among students.

9 Currently, Taiwan/Republic of China is recognized by the following states: Kiribati, Republic of the Marshall Islands, Nauru, Republic of Palau, Solomon Islands, Tuvalu, Burkina Faso, Democratic Republic of Sao Tome and Principe, Swaziland, Holy See, Belize, the Dominican Republic, El Salvador, the Republic of Guatemala, Haiti, the Republic of Honduras, Nicaragua, the Republic of Panama, Paraguay, Saint Christopher and Nevis, St. Lucia and Saint Vincent and Grenadines.

10 For example, in an introductory class to International Relations conducted by this author in spring 2015, besides local students, the class also hosted 2 students from Swaziland, 2 students from Gambia, 1 student from Nicaragua, 1 student from Vietnam, 1 student from Japan and 1 student from Paraguay. Swaziland, Nicaragua and Paraguay have formal diplomatic relations with Taiwan. Gambia terminated official relations with Taiwan in 2013. 


\section{Putting Taiwan in Context}

A look at the history of Taiwan since the Cold War period reveals that the island's past is placed amidst relations between China and the US. So called "Cross-strait Relations" came about following the Chinese Communist Party's (CCP) defeat of the Nationalist Party (KMT) in the Chinese civil war, a victory that led to the founding of a KMT regime in Taiwan that continued its resistance against the People's Republic of China. Thanks to US support since the Cold War period, Taiwan was able to keep China at bay. The normalization of relations between China and the US in 1979 dealt a major blow to Taiwan's international status, as the island nation was suddenly adrift in the world without the official support of its most important long term ally. Despite reconciliation of relations since 2008, China and Taiwan remain divided until this day.

Clearly, Taiwan's history suggests that the island nation's foreign relations are mainly based around China and the US. Other countries, regardless of their appeal, seem to fall out of comparison when historical context is considered. Teaching IR in Taiwan, therefore, often means devoting a substantial portion of the curriculum to bilateral relations between China and Taiwan (or so called "Cross-strait relations") and between the US and Taiwan. Another common way for observers to consider Taiwan's international relations is to understand its situation in terms of a triangular or three way relationship between the US, China and Taiwan, an approach that has generated many theoretical debates (Copper 1992; Tucker 2009; Lin and Roy 2011; Roy 2015). In short, Taiwan's international relations is heavily influenced and shaped by China and the US.

Noting its complicated history straddling the two powers, interestingly, over the years Taiwan has developed into a paradox in international relations that is difficult to characterize by any traditional standards. Culturally, the 23 million people on Taiwan, consisting mostly of ethnic Han Chinese, are closer to China than all other states in the world. However, politically, with its transition to a democratic system in the post-Cold War period, Taiwan has established a political system that shares more similarities with the US than China, most notably with its adoption of the direct presidential election in 1996. Considering the notion of "state," based on the juridical definition that a functioning government with control over specific territories, diplomatic capability and sovereignty constitutes a state, Taiwan is unarguably a state. Yet Taiwan's absence from the United Nations and lack of diplomatic recognition make the island nation seem closer to a pariah state such as North Korea than a normally established member of the international community. Finally, following export prosperity in the 1980s, Taiwan has since joined the ranks of developed economies in the world and stands in contrast with its counterpart across the Strait, ${ }^{11}$ despite the fact that the Chinese continental economy is several times larger than the island economy.

11 Taiwan stood among Hong Kong, Singapore and South Korea as one of four Tiger economies that sparked the East Asian economic miracle in the 1980 s. 
By placing Taiwan in the proper context presented above, one can start thinking about the island nation critically. For example, in terms of the "state" question, academics and political leaders remain in chronic debate over whether Taiwan is a state or not, to the extent that qualifications of de facto and de jure are used concurrently to define the status of the island (Bartmann, 2008). Resting on a somewhat ambiguous definition of the state, Taiwan's relationship with the world becomes dubious. If Taiwan is not a state, how should one characterize the island's relationship with other states? Should definition of the "state" be revised to include diplomatic recognition by other states? Should IR include non-state political entities as a separate category to be treated in its treatment of actors in global politics?

Regardless of the answers, the questions raised challenge the traditional construct of the state and stimulate reconsiderations for mainstream understandings based on specific contexts. While Taiwan may or may not be an exceptional case in international relations, a similar argument based on history and culture or context may be made by other states as well. In such sense, students should be made aware that concepts are supported by historical and cultural assumptions and be encouraged to constantly challenge the latter in search of better interpretations. Particularly in the global south, where cultural diversity and different histories are defining characteristics, context specific discussions may bring about different perspectives on international relations and examples for comparisions against different experiences, a move that may in turn improve the critical thinking ability of students.

\section{Realities and Alternative Realities of Taiwan}

A short survey of popular International Relations textbooks used in Taiwan exposes the fact that regarding theoretical engagement in classrooms, discussions rarely move beyond realist theory. For example, in Joshua Goldstein and Jon Pevehouse's (2011) International Relations, an introductory text commonly used in Taiwan, the authors devote a sole chapter to the discussion of realism while spending a chapter on liberalism and all other theories. In another popular text authored by local theorists also titled International Relations, once again, one finds realism to occupy an entire chapter at the beginning of the text while other theoretical discussions are condensed to one single chapter (Chang and Tso 2011). The disproportional emphasis on realism hints at the fact that the IR discipline in Taiwan is dominated by a strong realist discourse to the detriment of other perspectives.

While realism remains a useful analytic tool for understanding the functioning of international politics and foreign policy, overwhelming emphasis considerably risks the threat of simplifying theoretical debates in class and compressing the space for critical reflections among students. Beyond practical concerns hinged on power and interest - important variables in the game of great powers - realism offers little insights for states not within the ranks of the strong and developed (Chatterjee, 2012). In other words, in most cases, besides suggestions to increase 
(military) power, much of the global south has little to learn from realism. If the realities presented by realist theories are largely accurate reflections of international relations, the assumptions on power hint at major disadvantages for the global south that may be irreconcilable in any way in the near future. In addition, as Kenneth Waltz (2010) among others have suggested, major powers are the only important players in the world of international politics. In such case, in terms of the global south or much of the developing world, realism is likely to remain silent; small and middle powers are non-meaningful in international relations.

In the case of Taiwan, a small state or non-state with middle power economic capability, realist interpretations raise many interesting questions. For example, considering Taiwan's strategic position straddling China and the US - two of the biggest powers in the world today - whether in terms of reality or policy implications, realist theories do not provide much more than bleak analyses and hopelessness for Taiwan. Such argument was most persuasively explicated by John Mearsheimer's (2014b) article Say Goodbye to Taiwan, in which the author implies that there is little the island nation could do to save itself from disappearance from the world map. From the position of the weak, such claim may be self-defeating in the sense that no practical suggestions are made - a distinctive feature of realist theories. Moreover, following the logic of realism, perhaps the most Taiwan could do is to continue to increase its military power while recognizing the fact that the island nation stands little chance of saving itself from annihilation should conflict break out. Interpretations and predictions aside, the ultimate danger of such claim, however, is that coupled with a dominant realist discourse in local classrooms in Taiwan, students (and instructors alike) may be easily swayed into becoming supporters of the treatise without challenging its merits.

Regardless of various individual views that may or may not follow the realist tradition, the fact that reductive claims may be easily accepted and nearly uncontested in the realist dominant classroom is reason for instructors to hold doubts against the phenomenon. Without decrying the strengths of realist theory as an analytical tool and the inability of theories to be ever explanatory, noting the training of critical thinking skills as a goal of teaching IR, the instructor may need to make an effort to introduce alternative readings of realities in order to maintain a space for open debates and discussions that ultimately seeks to develop the intellectuals of students. While different interpretations that turn away from realism may not necessarily offer better descriptions of realities, the presence of multiple perspectives to balance against a dominant discourse is an important merit alone that should be valued. In the quest for logical reasoning and explanation, quite often the conclusion is cherished more than the process of discussion, which should be otherwise in the classroom.

While realist theory carves out a dim future for Taiwan, when other perspectives are considered, the world looks much brighter. For example, for the liberalists, increased trade and investment across the Taiwan Strait hints at growing interdependence between China and Taiwan that is averse to conflict (Rosen and Wang, 2011). On the other hand, European concepts on normalization and socialization may suggest China to be transforming as well through interactions 
with the world (Kent, 2002; Lynch, 2006; Hines, 2013). In such instance, Taiwan may have an important role to play in cultural exchanges with China. In short, regardless of theoretical correctness, the establishment of different standpoints for comparisons and discussions is an independent merit. In terms of the global south, preserving a space for discussions and debates may offer opportunities for critical reflections on an IR theories dominated by a northern or Anglo-Saxon discourse.

While the global south may not necessarily come up with radical understandings of the world that breaks away from mainstream interpretations, as suggested by William Brown (2006, 123), the fact that it is partaking in discussions represent a step towards pluralizing theoretical debates. As Ersel Aydinli and Julie Mathews (2008, 694) observed, "as long as the periphery is only on the receiving end of this division of labour, it will remain a weak, subservient partner in the discipline, and this imbalance will continue to limit the extent to which the discipline can achieve its goal of understanding global politics." Coupled with more considerations on history, culture and geography, it remains to be observed where discussions would lead to in terms of alternative theory building and interpretations in the future.

\section{Conclusion: Insights for the Global South}

This article is a brief attempt to make clear the importance of context when thinking about international relations and the need for contextualization in the IR classroom. In light of the goal to increase the critical thinking ability of students, contextualizing specifically refers to a thorough survey of the object(s) (usually the state) in discussion, looking at historical, cultural, geographic and other related elements that shape its development, before moving forward to accept general statements or so called "traditional wisdom."

A more comprehensive examination of the object(s) at hand not only allows students to consider specific issues or problems in a more roundabout manner, critical reflections on assumptions built into the issues may also be revealed. Reflections on underlying assumptions are especially important in terms of IR theory, which remains largely a Western domain. Only by introducing alternative perspectives and encouraging more discussions outside the domain, which unsurprisingly possesses a dominant discourse, would there be possibilities for other traditions to flourish. In terms of the global south, for students to be able to put the developing world in the context of separate historical developments and global change would be a shift away from the mainstream.

As the case of Taiwan demonstrates, the realist discourse is somewhat problematic despite its popularity on the island nation. A similar argument could be made for the dominance of foreign perspectives that threaten to crowd out local perspectives in the global south.

In light of the foregoing discussion, the following points may be taken into consideration when establishing a class that seeks to enhance critical thinking ability among students and 
diversify discussions on international relations by bringing the global south in. First, one should note the cultural diversity of student makeup in class and make efforts to address topics that speak to a variety of cultural backgrounds and the complexities of the world today. For example, while great powers may continue to be the focus for most issues, on non-traditional issues that affects all states, perhaps the views of small and middle powers could be introduced. Responses by the latter may be very different from major states. Second, the world map should be used during discussions of global issues. While the location of states such as the US, China and Russia can be easily identified without the visual support of a map, the same may not be said about states in the global south. In a sense, only by locating a state on the map can one begin to discern the historical and geographic implications of a specific locale. Finally, students should be encouraged to construct charts that note different perspectives on a specific subject in order to acknowledge various viewpoints. Besides the recognition of different stances, the organization process involved in chart making may greatly contribute to the development of critical thinking and problem solving skills.

\section{Bibliography}

Acharya, Amitav. "Dialogue and Discovery: In Search of International Relations Theories Beyond the West." Millennium: Journal of International Studies 39, no. 3 (2011): 619-637.

Aydinli, Ersel and Julie Mathews. "Periphery Theorising for a Truly Internationalised Discipline: Spinning IR Theory out of Anatolia.” Review of International Studies 34, no. 3 (2008): 693-712.

Bartmann, Robert. "Review Essay: Between De Jure and De Facto Statehood: Revisiting the Status Issue for Taiwan.” Island Studies Journal 3, no.1 (2008): 113-128.

Behera, Navnita Chadha. "Knowledge Production." International Studies Review (2016): 1-3. Blaney, David L. "Global Education, Disempowerment, and Curricula for a World Politics." Journal of Studies in International Education 6, no. 3 (2002): 268-282.

British Council. "Vision 2020: Forecasting International Student Mobility." http://www. britishcouncil.org/sites/britishcouncil.uk2/files/vision-2020.pdf

Brown, William. "Africa and International Relations: A Comment on IR Theory, Anarchy and Statehood." Review of International Studies 32, no. 1 (2006): 119-143.

Chang, Ya-Chung and Chen-Dong Tso eds. Guojiguanxi (International Relations). Taipei: YangChih Books, 2011.

Chatterjee, Aneek. “Theorizing the Global South in IR: Problems and Prospects.” Paper presented at the First Global South International Studies Conference at Menton, France, 2012.

Chen, Ching-Chang. "The Im/Possibility of Building Indigenous Theories in a Hegemonic Discipline: The Case of Japanese International Relations." Asian Perspective 36, no. 3 (2012): 463-492. 
Copper, John F. China Diplomacy: The Washington-Taipei-Beijing Triangle. Boulder, CO: Westview Press, 1992.

Copper, John F. Playing with Fire: The Looming War with China over Taiwan. Westport: Praeger Security International, 2006.

Dam, Geert ten and Monique Volman. "Critical Thinking as a Citizenship Competence: Teaching Strategies." Learning and Instruction 14 (2004): 359-379.

Deardorff, Michelle. “The Professor, Pluralism and Pedagogy: A Reflection.” Journal of Political Science Education 9 (2013): 366-373.

Friedman, Thomas. The World is Flat 3.0: A Brief History of the Twenty-first Century. New York: Picador, 2007.

Frueh, Jamie, David L. Blaney, Kevin Dunn, Patricia Goff, Eric K. Leonard and Simona Sharoni. "Political Beliefs and the Academic Responsibilities of Undergraduate Teaching." Journal of Political Science Education 4 (2008): 447-462.

Goldstein, Joshua and Jon Pevehouse. International Relations. New York: Pearson, 2011.

Hansen, Lene. “The Little Mermaid's Silent Security Dilemma and the Absence of Gender in the Copenhagen School." Millennium: Journal of International Studies 29, no. 2 (2000): 285-306.

Hines, Lincoln. "China, the ARF, and the South China Sea: Is China Being Socialized?" International Affairs Review 21, no. 2 (2013): 2-23.

Huntington, Samuel. "The Clash of Civilizations?” Foreign Affairs 72, no. 2 (1993): 22-49. Huntington, Samuel. The Clash of Civilizations and the Remaking of World Order. New York: Simon \& Schuster, 2011.

IMF World Economic Outlook Database. <http://www.imf.org/external/pubs/ft/weo/2015/01/ weodata/index.aspx>.

Japan Student Service Organization (JASSO). "International Students in Japan 2014," <http://www.jasso.go.jp/statistics/intl_student/data14_g_e.html>.

Jung, Min-ho. "Korea to Lure More Foreign Students.” The Korea Times, July 7, 2015.

Kayaoglu, Turan. "Westphalian Eurocentrism in International Relations Theory." International Studies Review 12, no. 2 (2010): 193-217.

Kent, Ann. "China's International Socialization: The Role of International Organizations." Global Governance 8 (2002): 343-364.

Keohane, Robert. After Hegemony: Cooperation and Discord in the World Political Economy. Princeton: Princeton University Press, 2005.

Keohane, Robert and Joseph Nye. Power and Interdependence. New York: Pearson, 2011.

Keohane, Robert, Joseph Nye and Stanley Hoffman eds. After the Cold War: International Institutions and State Strategies in Europe, 1989-1991. Cambridge, MA: Harvard University Press, 1993.

Leira, Halvard. "International Relations Pluralism and History - Embracing Amateurism to Strengthen the Profession.” International Studies Perspective 16, no. 1 (2015): 23-31. 
Lin, Cheng-yi and Denny Roy eds. The Future of United States, China and Taiwan Relations. New York: Palgrave Macmillan, 2011.

Ling, L. H. M. "Decolonizing the International: Towards Multiple Emotional Worlds." International Theory 6, no. 3 (2014b): 579-583.

Ling, L. H. M. "Hypermasculinity on the Rise, Again: A Response to Fukuyama on Women and World Politics.” International Feminist Journal of Politics 2, no. 2 (2000): 278-286.

Ling, L. H. M. Imagining World Politics: Sihar \& Shenya, a fable for our times. New York: Routledge, $2014 \mathrm{a}$.

Lynch, Daniel. Rising China and Asian Democratization: Socialization to "Global Culture" in the Political Transformations of Thailand, China and Taiwan. Stanford: Stanford University Press, 2006.

Mearsheimer, John. The Tragedy of Great Power Politics (Updated Edition). New York: W.W. Norton, $2014 \mathrm{a}$.

Mearsheimer, John. "Say Goodbye to Taiwan." National Interest (March/April 2014), <http://nationalinterest.org/article/say-goodbye-taiwan-9931>.

Morgenthau, Hans. Politics Among Nations. New York: McGraw-Hill Education, 2005.

Naim, Moises. The End of Power: From Boardrooms to Battlefields and Churches to States, Why Being In Charge Isn't What It Used to Be. New York: Basic Books, 2014.

National Institution for International Education (Korea). "Study in Korea," <http://www. studyinkorea.go.kr/en/sub/overseas_info/korea_edu/edu_student.do>.

Nye, Joseph. The Future of Power. New York: Public Affairs, 2011.

Nye, Joseph. Soft Power: The Means to Success in World Politics. New York: Public Affairs, 2005.

Project Atlas. "About Project Atlas." <http://www.iie.org/Research-and-Publications/ProjectAtlas/About>.

Puchala, Donald. "Some Non-Western Perspectives on International Relations." Journal of Peace Research 34, no. 2 (1997): 129-134.

ROC Ministry of Education. Education in Taiwan 2013/2014. Taipei: Ministry of Education, 2013.

Ross, Robert. "The 1995-1996 Taiwan Strait Confrontation: Coercion, Credibility and Use of Force." International Security 25, no. 2 (2000): 87-123.

Rosen, Daniel H. and Zhi Wang. "The Implications of China-Taiwan Economic Liberalization." Policy Analyses in International Economics no.93 (January 2011).

Roy, Denny. "Collision Course: The Looming U.S.-China Showdown over Taiwan." National Interest (February 2015), http://nationalinterest.org/feature/collision-course-the-loomingus-china-showdown-over-taiwan-12293

Shakirova, D.M. “Technology for the Shaping of College Students' and Upper-Grade Students' Critical Thinking." Russian Education \& Society 49, no.9 (2007): 42-52.

Smith, Karen. "Has Africa Got Anything to Say? African Contributions to the Theoretical Development of International Relations." The Round Table 98, no.402 (2009): 269-284. 
Snyder, Lisa Gueldenzoph and Mark J. Snyder. "Teaching Critical Thinking and Problem Solving Skills.” The Delta Pi Epsilon Journal 50, no. 2 (2008): 90-99.

Tickner, J. Ann. "Dealing with Difference: Problems and Possibilities for Dialogue in International Relations." Millennium: Journal of International Studies 39, no. 3 (2011): 607-618.

Tucker, Nancy Bernkopf. Strait Talk: United States-Taiwan Relations and the Crisis with China. Cambridge, MA: Harvard University Press, 2009.

Waltz, Kenneth. Theory of International Politics. Long Grove: Waveland Press, 2010.

"International Students in the United States." <http://www.iie.org/Services/Project-Atlas/UnitedStates/International-Students-In-US>. 